\title{
Depression in older adults: prevalence and risk factors in a primary health care sample
}

\author{
U Padayachey ${ }^{a *}$, S Ramlalla and J Chipps ${ }^{\mathrm{bc}}$ (D) \\ ${ }^{a}$ Department of Psychiatry, College of Health Sciences, University of KwaZulu-Natal, Durban, South Africa \\ ${ }^{b}$ Faculty of Community Health, University of the Western Cape, Cape town, South Africa \\ 'Honorary, Sydney School of Nursing, University of Sydney, Sydney, Australia \\ *Corresponding author, email: uschenkamsr@gmail.com
}

Background: Depression in the geriatric population has been identified as a significant problem in view of the associated negative outcomes regarding poor functioning, increased perception of poor health and increased utilisation of medical services. Significantly associated with increased morbidity and mortality, depression has been found to be an independent cause of disability as well as adding to disability due to primary physical illnesses. Early identification and treatment of depression reduces medical costs and lessens caregiver burden. Epidemiological data and prevalence rates of geriatric depression in Africa are limited, although such data are vital to mobilise and plan government mental health initiatives aimed at screening and early intervention. Objective: To determine the prevalence of depression and associated clinical and socio-demographic factors amongst older adult patients attending a primary health care clinic in the Ethekwini District in Kwa-Zulu Natal, South Africa.

Methods: The 15-item Geriatric Depression Scale and a socio-demographic questionnaire were administered in English to 255 geriatric outpatients, randomly selected, at a local community clinic in Durban.

Data analysis: Data were analysed using SPSS version $23^{\oplus}$. Descriptive statistics were used to summarise the sample demographics and response rate and non-parametric statistics were used to test for associations and differences.

Results: A Cronbach's alpha for the GDS was calculated ( $p=0.793)$. Some $40 \%$ of participants screened positive for depression. Female gender, widowhood and a negative subjective health status rating were significantly associated with depression and marriage appeared to be protective $(p<0.001)$. Participants with a poor subjective health rating were 21 times more likely to be depressed and widowhood conferred an almost fourfold increased risk of being depressed, with widows at greater risk than widowers. No association between depression and specific medical conditions was identified.

Conclusion: There is a high rate of undetected depression among the elderly attending a local primary health care clinic with widowhood and poor subjective health being strong predictors of mood disorders. The findings warrant replication in bigger samples.

Keywords: depression, elderly, prevalence, self-rated health, widowhood

\section{Background}

Depression in the geriatric community population has been identified as a significant problem in view of the negative outcomes regarding poor functioning, increased perception of poor health and increased utilisation of medical services. ${ }^{1}$ Identification and treatment of depression in the elderly is important because of its association with increased morbidity and mortality. It is specifically linked to an increased risk of stroke, heart failure and hip fractures. Depression has been found to be an independent cause of disability as well as contributing to disability from a primary physical illness by exacerbating physical deterioration. Early identification and treatment of depression serves to reduce additional medical costs incurred by depressed individuals and lessen the significant associated caregiver burden. ${ }^{2}$

Ageing presents with a multitude of organic changes that result in characteristic affective and behavioural patterns, often inadvertently viewed as part of the normal ageing process. ${ }^{3}$ Depression encompasses a range of mental issues and associated emotional, cognitive and behavioural symptoms. ${ }^{4}$ In addition, late life depression has typically mutable manifestations often masked by co-morbid medical conditions. ${ }^{5} \mathrm{~A}$ meta-analysis by Hegeman et al. in 2012 found that older adults are more likely to present with agitation, somatic complaints and hypochondriasis in addition to having no significant association with family history of depression or other mental illness. ${ }^{6}$ Together, these factors confound the accurate diagnosis and hence treatment of depression in this vulnerable population.

Globally, the average life expectancy has increased from 68 years in 1990 to 72 years in 2009, 7 with steadily increasing trends noted in developed countries. ${ }^{8}$ Due to this increase and the subsequent escalating burden of chronic diseases, a focus on mental health disorders in older adults is essential due to their impact on morbidity, mortality and quality of life. ${ }^{9}$ The Global Burden of Disease Study has predicted that depressive disorders will be a leading cause of disability by 2020 due to their significant impact on functioning and quality of life. ${ }^{10}$ Worldwide it is estimated that 350 million individuals suffer from depression. ${ }^{11}$ Approximately 5 million older adults worldwide experience late-onset depression but it still remains under-recognised and inadequately treated. ${ }^{12}$

Depression is found to persist into older age with the prevalence increasing with age. A meta-analysis of studies of individuals older than 75 years revealed the point prevalence of major depression to be $7.2 \%$; rates for women ranged between $4.0 \%$ and $10.3 \%$ and for men between $2.8 \%$ and $6.9 \% .{ }^{9}$ The prevalence of major depression is estimated to be between $10 \%$ and $20 \%$ in the general elderly population ${ }^{13}$ and $5 \%$ and $17 \%$ in primary care 
settings. ${ }^{14}$ The Cache County Study estimated the point prevalence rate of major depression in older adults in the community as $4.4 \%$ for women and $2.7 \%$ for men $^{9}$ while the Epidemiologic Catchment Area Survey reported a prevalence rate of $2.5 \%{ }^{15}$

In SA, the prevalence of major depression is reportedly higher at $27 \%$ in rural settings ${ }^{16}$ and $25.2 \%$ in urban settings. ${ }^{17}$ The SASH Study, a nationally representative household survey conducted in South Africa between 2002 and 2004 reported the lifetime prevalence rate of major depression to be $9.7 \%$ with a significant association with female gender. ${ }^{18}$ The 2008 SAGE study, a national population-based cross-sectional study in older South Africans, reported a $4 \%$ 12-month prevalence of symptom-based depression. ${ }^{19}$

Sub-threshold depression is diagnosed when a core symptom of depression and between oen and three additional symptoms is present and is of clinical significance due to the associated impairment in social and occupational functioning which is similar to that of major depression. ${ }^{9}$ The prevalence of depressive symptoms is reportedly higher than for major depression, with a recent meta-analysis reporting a rate of $19.47 \%$ for depressive symptoms. ${ }^{20}$ Sub-threshold depression is experienced by $15-$ $27 \%$ of older adults in community settings and $37 \%$ in primary care settings. ${ }^{15}$

In South Africa, the prevalence of depressive symptoms in rural settings is $18 \% .^{16}$ However, the recently published INK Study conducted in older adults living in a low resource, peri-urban area in South Africa reported a 50\% prevalence of depressive symptoms. ${ }^{21}$ This prevalence rate, as noted by the authors, is unusually high in comparison with other local and international findings and is attributed to the unique stressors encountered by the elderly in their study sample.

Limited epidemiological data and prevalence rates of geriatric depression are available from Africa even though such data are vital to mobilise and plan government mental health initiatives aimed at screening and early intervention. ${ }^{22}$ The aim of this study was to determine the prevalence of depression, depressive symptoms and associated clinical and socio-demographic factors amongst older adult patients attending a primary health care clinic in the Ethekwini District in Kwa-Zulu Natal (KZN).

\section{Methods}

\section{Setting}

The study was conducted at a primary health care clinic located in a middle-class suburb in Ethekwini, Kwa-Zulu-Natal, South Africa. The clinic serves the local geriatric population and includes residents of surrounding informal settlements.

\section{Design}

A quantitative descriptive survey using an investigatoradministered questionnaire was conducted. Ethical approval was obtained from the Bio-ethics Research Committee of the University of KZN. Permission to conduct the research was obtained from the local municipality and the KZN Provincial Department of Health.

\section{Sampling and population}

Approximately 300 older adult patients of varying ethnicity attend the Sydenham Heights Community clinic weekly. Participants aged 60 years and older, proficient in English, who attended the clinic during November and December 2014 constituted the study population. The sample size was calculated using an estimated prevalence $(p)$ of $21 \%^{23}$ for depression, $80 \%$ power, an error or precision range (c) from $5 \%$ to $8 \%$, and $95 \%$ confidence limits $(z=1.96)$ using the sample formula $s s=\left(z^{*} z(p)(p-1)\right) /\left(c^{*} c\right)$. A sample of 255 was needed to detect prevalence adequately. A systematic random sampling technique was employed.

\section{Instrument}

A sociodemographic questionnaire, which included 27 items, and the 15-item geriatric depression scale (GDS) were administered to all participants.

Geriatric Depression Scale (GDS): For the purposes of early intervention, the use of a validated screening tool is essential. The most commonly used depression screening tools for older adults are the 15- and 30-item Geriatric Depression Scales (GDS) and the Centre for Epidemiological Studies Depression Scale (CES-D). The CES-D scale uses an optimum cut-off score of 21 and yields a sensitivity of $92 \%$ and a specificity of $87 \%$. In comparison, the GDS-30 scale, using a cut-off of 10 , yields a sensitivity of $100 \%$ and a specificity of $84 \%$. The GDS-15 using a cut-off of 5 yields a sensitivity of $92 \%$ and a specificity of $81 \% .{ }^{24}$ A systematic review assessing the screening accuracy of both versions of the GDS was conducted by Wancata et al., 2006, and concluded that both versions of the scale were similar concerning their criterion validity. ${ }^{25}$ In addition, validity indices were compared with the CES-D and revealed similar criterion validity. Locally, a validation study by Ramlall et al. in 2013 supported the use of both versions of the GDS without significant influence on its performance due to race, age, gender or level of education. ${ }^{26}$

\section{Data collection}

Data were collected during November and December 2014. The purpose and nature of the study was explained to the staff and all clinic attendees. A systematic randomised sampling technique was employed. Individual patient information sheets were administered and patients were invited to participate. Participants self-completed the GDS and the socio-demographic questionnaire was researcher administered. Individuals found to have probable depression according to the GDS (score > 10) were referred to the local district hospital for psychiatric intervention and psychological support. Individuals identified as having possible depression (GDS scores of 5-9) were offered a referral to the district hospital for psychological support.

\section{Data analysis}

Data were analysed using SPSS version $23^{\circledR}$ (IBM Corp, Armonk, NY, USA). A Cronbach's alpha for the GDS was calculated ( $p=$ 0.793). Descriptive statistics such as frequencies, percentages and measures of central tendency were used to summarise the sample demographics and response rate. Pearson's chi-square test and Mann-Whitney $\mathrm{U}$ tests were used to test whether there is any association between the depression categories and the depression score and the risk factors. The level of significance was set at 0.05 . GDS items $1,5,7,11$, and 13 were reversed and a total score calculated. Participants were categorised as being not depressed (GDS $<5$ ); those scoring $\geq 5$ on the GDS were classified as being depressed with a sub-classification of mildly depressed (GDS 5-9) and moderate-severely depressed (GDS 10-15). A logistic regression analysis was conducted to adjust for significant demographic variables to determine the most significant predictor of depression in this group. 


\section{Results}

\section{Demographic and socio-economic profile}

A total of 255 patients participated in the study. Of these, 180 (70.6\%) were female and 75 (29.4\%) were male. The mean age of the participants was 69.9 years (SD 6.7), ranging from 58 to 91 years of age with no significant difference in the mean age between males and females (69.6 years vs. 69.9 years; $U=0.6$, $p=0.560$ ). More than $50 \%$ of participants were single, divorced or widowed $(147,58.6 \%)$ with 103 (40.4\%) being widowed. Some $81 \%$ (208) of participants lived with a spouse or other family members. The majority $(239 ; 93.7 \%)$ of participants had formal schooling with $139(56.7 \%)$ having a secondary level of education and 4 (1.6\%) having tertiary-level education. Nearly all participants $(243,95.3 \%)$ relied on a government pension as their sole source of monthly income.

\section{Clinical profile}

Just under half of the participants, $(119 ; 46.6 \%)$ self-rated their health as being 'poor'. Nearly all the participants (245, 96.1\%) reported at least one physical health problem with an average of 1.8 (range $0-4$ ) conditions reported per participant. Over $80 \%$ of participants reported that they had hypertension $(211 ; 82.7 \%)$, and nearly half reported that they had diabetes (105; 41.2\%). A quarter of participants $(66 ; 25 \%)$ stated that they suffered from conditions other than diabetes or hypertension. Similarly, almost all participants $(248 ; 97.3 \%)$ reported using chronic prescription

Table 1: Demographic profile of depressed vs. non-depressed participants

\begin{tabular}{|c|c|c|c|c|}
\hline \multirow[t]{3}{*}{ Factor } & $\begin{array}{c}\text { Not } \\
\text { depressed }\end{array}$ & Depressed & Test & $p$-value \\
\hline & GDS < 5 & GDS 5-15, & & \\
\hline & $\begin{array}{l}n=154 \\
(60.4 \%)\end{array}$ & $\begin{array}{l}n=101 \\
(39.6 \%)\end{array}$ & & \\
\hline Age & 69.5 (SD 6.9) & 70.05 (SD 6.7) & $U=1.4$ & $p=0.153$ \\
\hline \multicolumn{5}{|l|}{ Gender } \\
\hline Males $(n=75)$ & $52(33.8 \%)$ & $23(22.8 \%)$ & $X^{2}=3.6$ & $p=0.060$ \\
\hline $\begin{array}{l}\text { Females } \\
(n=180)\end{array}$ & $102(66.2 \%)$ & 78 (77.2\%) & & \\
\hline \multicolumn{5}{|l|}{ Marital status } \\
\hline $\begin{array}{l}\text { Never married } \\
(n=30)\end{array}$ & $20(66.7 \%)$ & 10 (33.3\%) & & \\
\hline $\begin{array}{l}\text { Divorced } \\
(n=14)\end{array}$ & $7(50 \%)$ & $7(50 \%)$ & $X^{2}=23.8$ & $p<0.001$ \\
\hline $\begin{array}{l}\text { Widowed } \\
(n=103)\end{array}$ & 45 (43.7\%) & $58(56.3 \%)$ & & \\
\hline $\begin{array}{l}\text { Married } \\
(n=108)\end{array}$ & 82 (75.9\%) & $26(24.1 \%)$ & & \\
\hline \multicolumn{5}{|l|}{ Living situation } \\
\hline $\begin{array}{l}\text { With others } \\
(n=208)\end{array}$ & $130(62.5 \%)$ & 78 (37.5\%) & $X^{2}=4.5$ & $p=0.135$ \\
\hline Alone $(n=47)$ & $24(51.1 \%)$ & $23(48.9 \%)$ & & \\
\hline \multicolumn{5}{|l|}{$\begin{array}{l}\text { Level of } \\
\text { education }\end{array}$} \\
\hline $\begin{array}{l}\text { Primary } \\
(n=102)\end{array}$ & $62(60.8 \%)$ & 40 (39.2\%) & $X^{2}=0.4$ & $p=0.849$ \\
\hline $\begin{array}{l}>\text { Primary } \\
(n=143)\end{array}$ & 88 (61.5\%) & 55 (38.5\%) & & \\
\hline \multicolumn{5}{|l|}{$\begin{array}{l}\text { Previous } \\
\text { employment }\end{array}$} \\
\hline Yes $(n=142)$ & $83(58.5 \%)$ & 59 (41.5\%) & $X^{2}=0.4$ & $p=0.550$ \\
\hline No $(n=111)$ & 69 (62.2\%) & $42(37.8 \%)$ & & \\
\hline
\end{tabular}

medication. Of these, 200 (78.4\%) participants reported that they were currently using up to 4 chronic medications and 51 (20\%) participants reported using between 5 and 9 different prescription medications. Very few $(21 ; 8.2 \%)$, reported using non-prescription drugs. Low levels of smoking and alcohol consumption were also found with $41(16.1 \%)$ and 29 (11.4\%) participants reporting smoking and alcohol consumption respectively.

\section{Prevalence and correlates of depression}

The mean GDS score for the sample was 4.3 (SD 3.2) with the scores ranging from 0 to 13 . There were significant differences in the GDS score by gender, with males scoring significantly lower (3.6, SD 3.0) than the females (4.6, SD 3.2) $(U=2.4, p=0.016)$.

Using a cut-off score of 10 or more, 22 (8.6\%) participants were classified as moderately-severely depressed and 79 (31\%) scoring between 5 and 9 were classified as mildly depressed. Altogether, $53 \%(135,52.9 \%)$ of the participants reported between 1 and 4 symptoms (likelihood of sub-syndromal depression), with 19 (7.5\%) reporting no depressive symptoms. Of the total sample of 255, 101 (39.6\%) participants scored 5 or more on the GDS consistent with a $39.6 \%$ prevalence of probable to possible depressive disorder in this sample.

In examining the association of demographic characteristics and depression (GDS $\geq 5$ ), a near association is seen with gender with $30.7 \%$ of the males as opposed to $43.3 \%$ of females being depressed, $p=0.060$. A strong association between depression and widowhood was found ( $56.3 \%$ vs. $43.7 \%, p<0.001)$, which was driven by more widows being depressed $(66.7 \%$ vs. $38.2 \%$, $p<0.001)$. Being married was strongly associated with not being depressed $(75.9 \%$ vs. $24.1 \% ; p<0.001)$. There was no significant association with depression and education level or previous employment status (Table 1).

Ten participants reported a past psychiatric history, and five participants identified themselves as either currently depressed $(n=4)$ or on treatment for depression $(n=1)$. The GDS scores for these 5 participants were $3(n=2), 6(n=2)$ and $1(n=1)$.

Table 2: Clinical profile of depressed vs. non-depressed participants

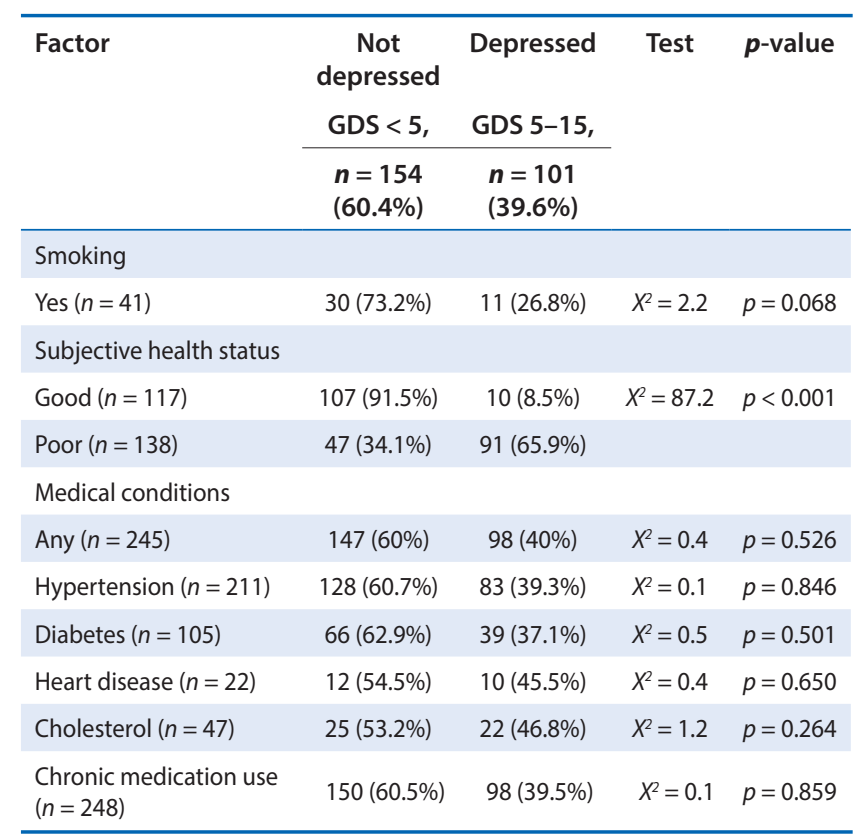


There were no significant associations between depression and medical conditions (hypertension, diabetes, heart disease and hypercholesterolemia) or depression and chronic medication use (Table 2). A significant association was found between participants reporting a subjective health rating of 'poor' and being classified with depression $(p<0.001)$ (see Table 2$)$ with 91 $(90.1 \%)$ of the depressed participants rating their health status as poor and a higher proportion of participants with poor subjective health being depressed compared with those who rated their health as good $(65.9 \%$ vs. $34.1 \%, p<0.001)$.

Direct logistic regression was performed to assess the impact of a number of factors on the likelihood that the participants will be categorised as suffering from depression. The model contained four independent variables (gender, living alone, marital status, subjective poor health). The full model containing all the predictors was statistically significant, chi-square $(3, n=255$, $100.1, p<0.001$, indicating that the model was able to differentiate between participants with depression and without depression. The model as a whole explained between $32.5 \%$ (Cox and Snell R squared) and $44.0 \%$ (Nagelkerke R squared) of the variance in depression categories, and correctly classified $77.6 \%$ of the cases. Two variables made a unique statistically significant contribution to the model (subjective health status and being widowed), recording an odds ratio of 20.8 and 3.9 respectively. This indicated that the participants who reported a subjective poor health status were 21 times more likely to be depressed and those who were widowed were nearly 4 times more likely to be depressed. Further, of the 101 depressed individuals as per GDS scores (23 males and 78 females), 6/23 (26.1\%) males were widowed and 52/78 (66.7\%) females were widowed, Fisher's exact chi-square $=21.2, p<0.001$, highlighting that widowed females are at greater risk than widowed males.

\section{Discussion}

Depression in the geriatric population is known to be significantly associated with negative outcomes. ${ }^{1}$ Early identification at primary care level is essential as depression is treatable. This study provided a measure of the burden of depression and depressive symptoms in the elderly using the 15 item Geriatric Depression Scale.

Consistent with studies from developing countries in similar settings, our study yielded a prevalence rate for depression of approximately $40 \%$, which is similar to that of an Indian study $(40.6 \%)^{27}$ but higher than a South Korean study $(27.8 \%) .^{15}$ Both studies used the GDS-15 to screen for depression. These figures are slightly lower than the prevalence figures determined by the 2015 INK community study in Durban, South Africa, which reported a $50.1 \%$ prevalence of depressive symptoms in older adults living in a low-resource peri-urban area in South Africa. ${ }^{21}$ Notably, the CES-D 10 scale was employed in the INK study; while it has a validated algorithm to determine possible depressive symptoms it does not confer a diagnosis of depression. The lack of consistent instruments, different study populations and sociodemographic profiles between the INK study and our study limits comparison of findings between the two local studies.

The strongest association with depression in our study was found to be with self-rated health status. Self-rated health is documented as a predictor of survival and is now commonly considered in studies of the elderly. ${ }^{28}$ Bond et al. (2006), investigated the prognostic capacity of this measure and reported that self-rated health was associated with a higher risk of death, and functional and cognitive impairment. ${ }^{29}$ Depression is known to have a negative association with perceived health status in the elderly and Kim et al. (2009) note that perceived health status is the most powerful predictor of depression in the elderly. ${ }^{23}$ This finding is consistent with the highly significant association found with a negative rating of subjective well-being and depression in our study. After adjusting for gender and living on one's own, negative subjective health status was the strongest predictor of depression in the older adult. In resource-constrained local settings where mental health professionals are scarce, determination of subjective health status therefore has the potential to serve as a screening measure by lay community-based workers; screen positives could then be referred to nursing personnel for formal screening. As a proxy for depression in our sample, poor subjective health status has a sensitivity of $90 \%(82.1-94.9 \%)$ and a specificity of $69.5 \%(61.5-76.5 \%)$ against the GDS.

Olivera et al. (2011) highlight the significant association of female gender with the prevalence of psychogeriatric symptomatology. The association between female gender and affective disorders is clearly established with differences attributed to hormonal and psychosocial factors..$^{30}$ Our study revealed a near association between gender and depression with an increased prevalence in women, thus supporting female gender as a risk factor for the development of late-life depression. In addition, there were significant associations with gender and other risk factors with nearly $80 \%$ of the female participants being economically dependent and widowed (nearly 70\%).

Personality attributes; life and social stressors; single, divorced or widowed status; bereavement; and learned helplessness are thought to be psychosocial risk factors for the development of depression. ${ }^{31}$ Loneliness as a natural part of ageing is a direct consequence of loss usually through death or abandonment and is viewed by the older adult as a precursor to depression as well as a self-imposed withdrawal. ${ }^{32}$ The association between loneliness and the course of depression in older persons was explored in a two-year follow-up study in the Netherlands, which concluded that the prognosis of late-life depression is adversely affected by loneliness. ${ }^{33}$ Our study revealed no significant association between living alone and depression, suggesting that the participants maintain active social networks despite living alone or that living alone cannot serve as a proxy for loneliness.

Widowhood refers to a long-term state following the experience of death of a significant other, which has social and personal consequences. ${ }^{34}$ Our study found that participants who were widowed were nearly twice as likely to be classified as depressed as compared with their married counterparts, with widowed females having twice the risk of depression. This could be attributed to the overlap of symptoms of depression and bereavement as well as the unique stressors of South African women. This significant association is supported by Onrust et al., where a prevalence rate of depression of $22 \%$ in the first year was identified in widowed subjects. ${ }^{35}$ The widowhood effect, which is the increased likelihood for a recently widowed individual to die, is a direct reflection of the impact of social relations on health. ${ }^{36}$ The widowed elderly should therefore be closely supported and monitored for depression to reduce the negative health outcomes associated with depression.

Similarly, numerous empirical studies demonstrate that marital dissolution is associated with severe social discord and confers an increased risk for psychological distress and overall mortality. ${ }^{37}$ This study identified that $50 \%$ of divorced participants were depressed. 


\section{Limitations}

To our knowledge, this is the first study to explore the presence of depression and depressive symptoms in a primary care elderly population. While our findings cannot be generalised to all elderly primary care populations, it provides a snapshot of the clinical and risk profile of those with depression. However, the prevalence in this study is comparable with international studies. Cultural issues influence the presentation and detection of depression and exclusion of non-English-speaking participants limits the generalisability of our findings. While self-report may inhibit disclosure due to stigma, one can equally expect an exaggeration of distress in those who may have been depressed. Ideally, clinical corroboration of GDS assessments by a comprehensive mental state examination is the ideal but was beyond the scope of this project.

\section{Conclusion and recommendations}

Safe treatment options for depression in the elderly are accessible, available and cost-effective, having the potential to reduce health care usage and increase health outcomes in the elderly with broader savings for health specifically and society in general.

This study revealed a $40 \%$ prevalence of depression in older adults in a primary care setting, identifying widowhood and negative subjective health assessments as significant predictors of depression. The potential use of subjective health status as a general-population-level screener is worthy of further exploration. Given the higher morbidity and mortality among the depressed elderly, greater awareness needs to be created at community and primary health care level to screen for and identify depression, especially in those identified as at high risk.

\section{ORCID}

\section{J Chipps (iD) http://orcid.org/0000-0002-7895-4483}

\section{References}

1. Bunce D, Batterham PJ, Mackinnon AJ, et al. Depression, anxiety and cognition in community-dwelling adults aged 70 years and over. J Psychiatr Res. 2012;46(12):1662-6. http://dx.doi.org/10.1016/j.jpsychires.2012.08.023

2. Hammami S, Hajem S, Barhoumi A, et al. Screening for depression in an elderly population living at home. Interest of the mini-geriatric depression scale. Rev Epidemiol Sante Publique. 2012;60(4):287-93. http://dx.doi.org/10.1016/j.respe.2012.02.004

3. Harding $S$, Lenguerrand $E$, Costa G, et al. Trends in mortality by labour market position around retirement ages in three European countries with different welfare regimes. Int J Public Health. 2013;58(1):99-108. http://dx.doi.org/10.1007/s00038-012-0359-8

4. Penninx BW, Milaneschi $Y$, Lamers $F$, et al. Understanding the somatic consequences of depression: biological mechanisms and the role of depression symptom profile. BMC Med. 2013;11:129. http://dx.doi.org/10.1186/1741-7015-11-129

5. Gureje O, Kola L, Afolabi E. Epidemiology of major depressive disorder in elderly Nigerians in the Ibadan Study of Ageing: a community-based survey. Lancet. 2007;370(9591):957-64. http://dx.doi.org/10.1016/S0140-6736(07)61446-9

6. Blazer DG. Depression in late life: review and commentary. J Gerontol Ser A. 2003;58(3):249-65. http://dx.doi.org/10.1093/ gerona/58.3.M249

7. World Health Statistics. Geneva: WHO; 2012. Available from: www. who.int/iris/bitstream/10665/44844/1/9789241564441_eng.pd.

8. Anderson GF, Hussey PS. Population aging: a comparison among industrialized countries. Health Aff (Milkwood). 2000;19(3):191-203. http://dx.doi.org/10.1377/hlthaff.19.3.191

9. Aziz R, Steffens DC. What are the causes of late-life depression? Psychiatr Clin North Am. 2013;36(4):497-516. http://dx.doi. org/10.1016/j.psc.2013.08.001
10. Schroeder M, Krebs MO, Bleich S, et al. Epigenetics and depression: current challenges and new therapeutic options. Curr Opin Psychiatr. 2010;23(6):588-92. http://dx.doi.org/10.1097/YCO.0b013e32833d16c1

11. Marcus $M$, Yasamy MT, van Ommeren $M$, et al. Depression: a global public health concern. Geneva: World Health Organization; 2012. 1-22013.

12. Viscogliosi G, Andreozzi P, Chiriac IM, et al. Depressive symptoms in older people with metabolic syndrome: is there a relationship with inflammation? Int J Geriatr Psychiatr. 2013;28(3):242-7. http://dx.doi.org/10.1002/gps.v28.3

13. Barua A, Ghosh MK, Kar N, et al. Prevalence of depressive disorders in the elderly. Ann Saudi Med. 2011;31(6):620-4. http://dx.doi.org/10.4103/0256-4947.87100

14. Cole MG, Bellavance F, Mansour A. Prognosis of depression in elderly community and primary care populations: a systematic review and meta-analysis. Am J Psychiatr. 1999;156(8):1182-9.

15. Park JH, Kim KW, Kim MH, et al. A nationwide survey on the prevalence and risk factors of late life depression in South Korea. J Affect Disord. 2012;138(1-2):34-40. http://dx.doi.org/10.1016/j.jad.2011.12.038

16. Rumble S, Swartz L, Parry C, et al. Prevalence of psychiatric morbidity in the adult population of a rural South African village. Psychol Med. 1996;26(5):997-1007. http://dx.doi.org/10.1017/S0033291700035327

17. Gillis LS, Welman M, Koch A, et al. Psychological distress and depression in urbanising elderly black persons. S Afr Med J. 1991;79:490-5.

18. Tomlinson M, Grimsrud AT, Stein DJ, et al. The epidemiology of major depression in South Africa: results from the South African stress and health study. S Afr Med J. 2009;99(5):367-73.

19. Peltzer K, Phaswana-Mafuya N. Depression and associated factors in older adults in South Africa. Global Health Action. 2013;6. doi: 10.3402/gha.v6i0.18871.

20. Smarr KL, Keefer AL. Measures of depression and depressive symptoms: Beck Depression Inventory-II (BDI-II), Center for Epidemiologic Studies Depression Scale (CES-D), Geriatric Depression Scale (GDS), Hospital Anxiety and Depression Scale (HADS), and Patient Health Questionnaire-9 (PHQ-9). Arthritis Care Res. 2011;63(Suppl 11):S45466. http://dx.doi.org/10.1002/acr.v63.11s

21. Narainsamy J, Chipps J, Cassim B. Depressive symptoms in communitydwelling persons aged $>60$ years in Inanda, Ntuzuma and KwaMashu in eThekwini, KwaZulu-Natal. S Afr J Psychiatr. 2015;21(1):13-8. http://dx.doi.org/10.7196/sajp.576

22. Stein DJ, Seedat S, Herman A, et al. Lifetime prevalence of psychiatric disorders in South Africa. Br J Psychiatr J Ment Sci. 2008;192(2):112-7. http://dx.doi.org/10.1192/bjp.bp.106.029280

23. Kim Jl, Choe MA, Chae YR. Prevalence and predictors of geriatric depression in community-dwelling elderly. Asian Nurs Res. 2009;3(3):121-9. http://dx.doi.org/10.1016/S1976-1317(09)60023-2

24. Lyness JM, Noel TK, Cox C, et al. Screening for depression in elderly primary care patients: a comparison of the Center for Epidemiologic Studies Depression Scale and the Geriatric Depression Scale. Arch Int Med. 1997;157(4):449-54. http://dx.doi.org/10.1001/ archinte.1997.00440250107012

25. Wancata J, Alexandrowicz R, Marquart B, et al. The criterion validity of the Geriatric Depression Scale: a systematic review. Acta Psychiat. Scand. 2006;114(6):398-410. http://dx.doi.org/10.1111/acp.2006.114.issue-6

26. Ramlall S. Screening for and diagnosing dementia in an elderly residential home population: a validation study; 2013, Unpublished data.

27. Bhamani MA, Karim MS, Khan MM. Depression in the elderly in Karachi, Pakistan: a cross sectional study. BMC Psychiatr. 2013;13:181. http://dx.doi.org/10.1186/1471-244X-13-181

28. Ocampo JM. Self-rated health: importance of use in elderly adults. Colomb Med. 2010;41(3):275-89.

29. Bond J, Dickinson HO, Matthews FE, et al. Self-rated health status as a predictor of death, functional and cognitive impairment: A longitudinal cohort study. Eur J Ageing. 2006;3(4):193-206. http://dx.doi.org/10.1007/s10433-006-0039-8

30. Olivera J, Benabarre $S$, Lorente $T$, et al. Detecting psychogeriatric problems in primary care: factors related to psychiatric symptoms in older community patients. Ment Health Fam Med. 2011;8(1):11-9.

31. Engel G. The clinical application of the biopsychosocial model. Am J Psychiatr. 1980;137:535-44. 
32. Barg FK, Huss-Ashmore R, Wittink MN, et al. A mixed-methods approach to understanding loneliness and depression in older adults. J Gerontol B Psychol Sci Soc Sci. 2006;61(6):S329-39. http://dx.doi.org/10.1093/geronb/61.6.S329

33. Holvast F, Burger $\mathrm{H}$, de Waal MM, et al. Loneliness is associated with poor prognosis in late-life depression: Longitudinal analysis of the Netherlands study of depression in older persons. J Affect Disord. 2015;185:1-7. http://dx.doi.org/10.1016/j.jad.2015.06.036

34. Bennett KM, Soulsby LK. Wellbeing in bereavement and widowhood. IIIn Crises Loss. 2012;20(4):321-37. http://dx.doi.org/10.2190/ IL.20.4.b
35. Onrust SA, Cuijpers P. Mood and anxiety disorders in widowhood a systematic review. Aging Ment Health. 2006;10(4):327-34. http://dx.doi.org/10.1080/13607860600638529

36. Elwert F, Christakis NA. Variation in the effect of widowhood on mortality by the causes of death of both spouses. Am J Public Health. 2008;98(11):2092-8. http://dx.doi.org/10.2105/AJPH.2007.114348

37. Gahler M. "To Divorce is to Die a bit..." A longitudinal study of marital disruption and psychological distress among Swedish women and men. Fam J Alex Va. 2006;14:372-82. http://dx.doi. org/10.1177/1066480706290145

Received: 22-08-2016 Accepted: 05-12-2016 